\title{
STOMOXYS CALCITRANS LINN, PART II.*
}

By Chas. K. Brain,

The Circulatory System.

The circulatory system in Stomoxys calcitrans consists, as in other Diptera, of the dorsal vessel or heart, and its anterior continuation, the thoracic aorta. The dorsal vessel extends as a delicate tube from the posterior part of the abdomen to its anterior sixth, that is above the anterior part of the sucking stomach, where it becomes narrowed into the thoracic aorta. This narrowed portion continues of uniform thickness until the proventriculus is reached, where it becomes somewhat flattened and wider. Beyond this it becomes narrower, and terminates above the esophagus, between the proventriculus and the neck.

It may be noticed that, as found by Professor Minchin in his study of Glossina sp., the dorsal vessel ends blindly behind, is composed of similar giant cells, and has similar ostia and alary muscles. The number of chambers in the heart was not determined with certainty, but I think Tulloch was correct in supposing that there were four. The dorsal vessel lies free in the pericardial cavity, but is supported by the muscular pericardial septum.

\section{Nervous System.}

There are two chief ganglia, viz: the brain and the thoracic ganglion, and from these the main nerve-trunks arise. Time was not taken to work out the more minute nerves, but the following may be mentioned. The chief nerves of the head beyond those of the compound eyes, are those which enervate (a) the antennae, (b) the ocelli, and (c) the esophagus, pharynx, and the pharyngeal muscles.

The brain is connected with the thoracic ganglion by commissures, between which the esophagus passes. The thoracic ganglion is roughly pear-shaped, and is supported by the internal chitinous skeleton of the thorax. The main nerves given off from the thoracic ganglion are (a) six pairs which

*The first part of this paper, which dealt with the external mouthparts and the digestive system, appeared in Vol. V, No. 4, pp. 421-430 of these Ansals, December, 1912. 
supply the thoracic muscles, and (b) the abdominal nerve trunk, which arises as a stout continuation of the posterior part of the ganglion. This nerve trunk gives off fine branches to the abdominal muscles and on reaching the third abdominal segment, splits into three.

These three branches supply the reproductive organs, the ovaries or testes, and the ovipositor or the penis.

\section{Reproductive System.}

The male generative organs, (Plate XXII, Fig. 7.) are comparatively simple in structure. They are however not readily seen in gross dissection until some of the surrounding and over-lying Malpighian tubules are moved. They consist of a penis, ejaculatory duct, vesicula seminalis, and testes with their ducts.

The testes are smooth, spherical bodies, enclosed in sacs which have deeply pigmented walls, giving them a deep orange color. From the lower end of each testis a delicate tube arises, short and straight, which runs down to join the duct from the opposite side, as the upper limbs of a $Y$.

From this junction an exceedingly short length of common duct enters the bulbous upper end of the tubular organ, which would seem to serve as a vesicula seminalis. This is a flexible tube, often. seen lying with one or two U-shaped bends in its course. At its upper end this vesicula seminalis is bulbous, gradually narrowing below to form the ejaculatory duct, (Fig. 7 , e. d.), which crosses the rectum dorsally from left to right, to enter the penis in front of it.

The female reproductive organs, (P1. XXII, Fig. 8) are of the house fly type. There are two ovaries, each consisting of some 60 ovarioles. The ovaries vary in size according to the degree of maturity of the lowest ova, of which there are never more than four in a single ovariole. In some cases the ovaries occupy more than half of the whole abdominal space. The ovarioles from one side open into a wide tubular duct which joins the similar duct from the other side like the arms of a $Y$.

As a result of this junction a common oviduct (o. v.) results, which runs down forming a long third limb to the $Y$. Below the attachment of the uterine appendages the oviduct continues as the uterus. The appendages consist of the uterine glands and the receptacula seminis. 
The uterine glands, (u. g.), are two rather stout tubular organs with slightly bulbous extremities. The bulbous end is firmly joined to the lateral oviduct by a very short double strain of connective tissue.

The receptacula seminis are two small, black, spherical bodies, each with a cellular socket resembling the fitting of an acorn cup. From this runs a very fine duct which enters the division between the oviduct and the uterus in the mid-dorsal line. The receptacula are attached to each other but can be separated by dissection. The uterus is a tube of the same diameter as the common oviduct above, and runs down the middle line into the ovipositor.

The ovipositor consists of three cylindrical segments of thin chitin which usually lie telescoped inside the abdomen.

\section{Habitat.}

Farmyards and stables are evidently the favorite haunts of this fly. It occurs also in fields and open woods, especially where cattle or horses are grazing. It is evidently by no means uncommon even in large cities, and numbers have been seen in quite busy streets. It is fond of resting on surfaces fully exposed to the sun, such as doors, gates, and rails, and to a less extent also on stone walls. Painted surfaces seem to be specially attractive to it. Its flight is quite inaudible at a short distance. When disturbed it frequently returns to the same spot, as though it were a favorite resting place. It is quite active during the warmer part of the day, and at night returns to some sheltered spot such as the beams in a shed. In Columbus the numbers of this species dwindled towards the end of October in 1912, but a few could be caught up to the end of November, and four specimens were taken on December $3 r d$. In captivity these flies live but a short time, generally less than a week. They frequently clean their wings, performing their cleaning with great precision, the hind pair of legs being used for this purpose. The lower surface is combed, then the upper, the legs are then rubbed together and the process repeated.

Emergence from the egg.

The larva makes its escape from the egg by splitting the broad end of the groove, leaving it slightly raised, and apparently intact on the opposite side, Plate XXII, Figure 1. 


\section{The Larva. Plate XXII, Figs. 2 and 3.}

Color creamy white to yellowish, shiny, greasy in appearance. The coiled alimentary tract, when filled with food, gives the posterior portion a dark appearance. The longitudinal tracheae may be recognized as two submedian white lines which show delicate lateral branches. The posterior stigmata are black, while the thoracic ones are yellowish in color.

In form the larva is elongate, tapering towards the head but broadly rounded behind. The segmentation is not very conspicuous, and the epidermis is bare, not having hairs nor bristles. On the head may be seen two large divergent mammiform processes, at the end of which are the minute retractile antennae, which are apparently each composed of four subequal segments. The mouth parts are strongly chitinised in the full grown larva and are composed of a number of sclerites as shown in Figs. 2 and 3.

The last seven segments are furnished, on their ventral surface, with raised bands of tactile tubercles. The posterior stigmata are two in number, circular, and somewhat distant from each other. The thoracic stigmata occupy a sub-lateral position on the third segment, and each consists of five circular orifices. (t. s.). These are connected with a large bilateral air sac which extends along the fourth segment.

Method of pupation.

The time taken for pupation is usually about two hours. The larva at first becomes quiet, and shortens rapidly, chiefly by the contraction of the anterior segments. In this way it assumes a form which resembles a barrel in shape. At this stage it is still yellowish white and the mouthparts of the larva are plainly visible through the soft integument. The color then changes to a bright yellow, and in about an hour longer it assumes the normal chestnut color of the puparium.

The puparium is from 5 to $6 \mathrm{~mm}$. in length, only eleven segments are visible, the anterior one bearing the minute, bilateral, thoracic stigmata, while the broadly rounded posterior segment shows the disc-like posterior stigmata. Under optimum conditions this stage lasts from 9 to 13 days.

Development of the adult.

About three days before the emergence of the adult fly, the cuticle of the puparium darkens, and eventually splits along the lateral and median lines, anteriorly, and trans- 
versely across the fourth segment. This section falls away and the fly escapes. Prior to this the nymph undergoes its final ecdysis, pushing its effete skin off backwards into the posterior end of the puparium. On its emergence it appears as a small dark fly, gray in color, with thick rudimentary wings of a dull leaden color. Its head is, at this stage, much wider than the thorax, and the abdomen is attenuated. At first it is very active, the period of activity evidently serving to allow the fly to force its way to the surface before the wings are fully grown and stiffened. The frontal sac is constantly inflated during this time, and no doubt serves in moving tragments of earth, etc. out of the way. When liberated the insect spends considerable amount of time in combing out the hairs on the arista of the antennae.

During this time the fly constantly changes its position, and the frontal sac is contracted. There are marked changes, too, in the abdomen and wings. The abdomen first becomes longer, and is constantly expanded and contracted, and gradually assumes its normal coloring, with the clove spots. The wings then begin to expand, a process which is completed in less than five minutes.

The fly is about its normal size, shape, and color at this time, but some time is taken in the final hardening of the integument, and in the final combing operations, which seem to be indispensible before flight. It is during this last process that the proboscis is at last raised into its horizontal position.

\section{REFERENCES.}

See Bibliography given in Part I, and also:

Newstead, R. 1907. Stomoxys calcitrans Linn. Ann. Trop. Med. and Parasit. Vol. I. 1907. Liverpool.

\section{DESCRIPTION OF PLATE XXII.}

Fig. 1. Egg, greatly enlarged, showing groove, and point of emergence of the iarva, $e$.

Fig. 2. Lateral view of anterior segments of larva, showing ant, antenna; $m$, mandible; $h . s .$, hypostomal sclerite.

Fig. 3. Dorsal view of anterior segments of larva of Stomoxys calcitrans. $m$, mandible; $t$. $s$., thoracic spiracle.

Fig. 4. Openings of thoracic spiracle.

Figs. 1, 2, 3 and 4. After Newstead.

Fig. 5. Semi-diagramatic view of adult fly. See Part I.

Fig. 6. Salivary glands and left Malpighian tube of adult, see Part I.

Fig. 7. Male reproductive organs: $t$, testis; $v$. $s$, vesicula seminalis; $e$. $d$., ejaculatory duct; $r$, rectum.

Fig. 8. Female reproductive organs: $o$, ovary; $o v$, oviduct; $u$. $g .$, uterine gland; $u$, uterus; $r$. s., receptacula seminis. 


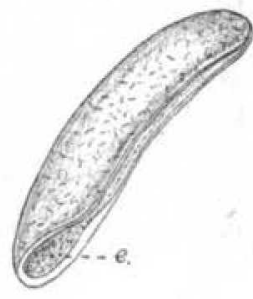

1.

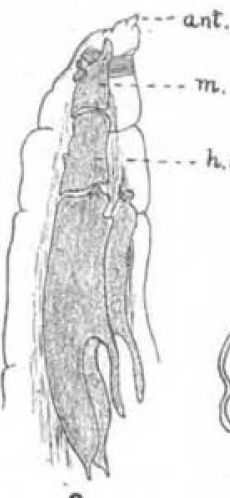

2

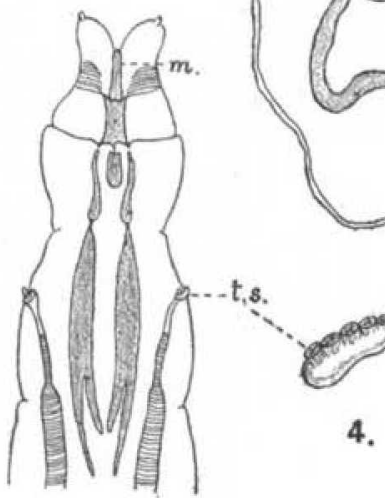

3.

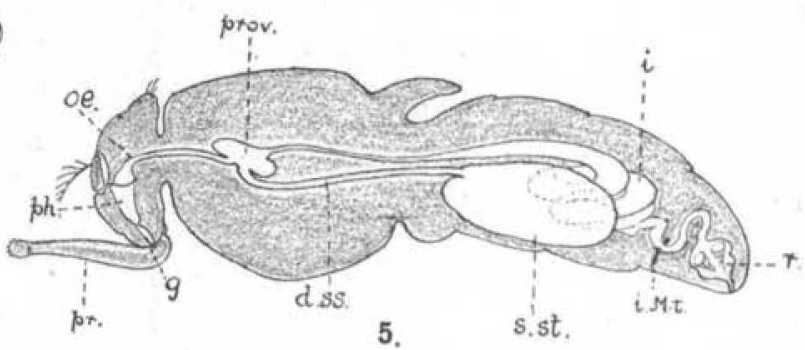



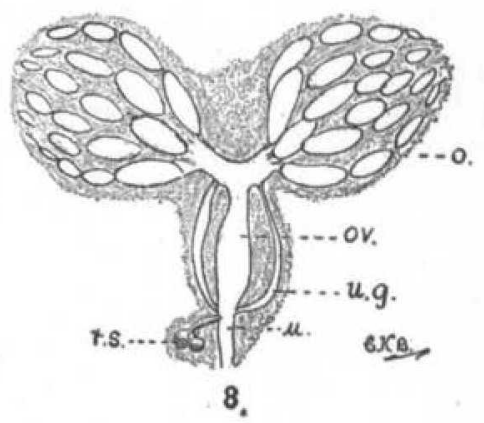

